\title{
Persentase Mortalitas Embrio Burung Puyuh yang Diberikan Ekstrak Daun Mengkudu sebagai Disinfektan Alami dalam Proses Penetasan
}

\author{
Percentage of Mortality in Quail Embryos Given Noni Leaf Extract as a Natural \\ Disinfectant in the Hatching Process
}

\author{
Isra Mirawati*, Muhammad Nur Hidayat, Khaifah Asgaf, Jumriah Syam, \\ Aminah Haja Thaha, Muh. Basir S.Paly, Andi Suarda, \\ Khaerani Kiramang, Mursidin, Rusny, Abbas \\ Jurusan Ilmu Peternakan, Fakultas Sains dan Teknologi, UIN Alauddin \\ Gowa-92113, Sulawesi Selatan, Indonesia. \\ *Korespondesi E-mail: isramirawati121296@gmail.com
}

\begin{abstract}
ABSTRAK
Penelitian ini bertujuan adalah untuk mengetahui pengaruh sanitasi alami ekstrak daun mengkudu (Morinda citrifoli lignosae) dengan metode pengelapan terhadap mortalitas embrio telur burung puyuh (Conturnix conturnix japonica). Penelitian ini menggunakan 1.500 butir telur tetas burung puyuh dengan rasio induk jantan dan betina 1:4. Penelitian ini menggunakan metode rancangn acak lengkap (RAL), dengan 3 perlakuan dan 3 ulangan masing-masing setiap ulangan terdiri dari 100 butir telur tetas burung puyuh dengan berat telur 10 gram. Perlakuan yang digunakan adalah $\mathrm{P}_{0}$ : kontrol, $\mathrm{P}_{1}$ : menggunakan desinfektan komersil : $8 \mathrm{~mL} / 1000 \mathrm{~mL}$ Air, $\mathrm{P}_{2}$ : konsentrasi 10\% $=10 \mathrm{~mL}$ estrak daun mengkudu $+90 \mathrm{~mL}$ Air suling. Hasil penelitian dengan penggunaan ekstrak daun mengkudu sebagai sanitasi alami dengan metode pengelapan diperoleh bahwa penggunaan ekstrak daun mengkudu 10\% tidak memberikan perbedaan pengaruh yang nyata terhadap mortalitas embrio $(\mathrm{P}>0.05)$. Meskipun demikian pada konsentrasi $10 \%$ dapat menurunkan mortalitas embrio $14 \%$. Kesimpulan dari penelitian ini yaitu penggunaan ekstrak daun mengkudu dapat mempengaruhi mortalitas embrio.
\end{abstract}

Kata kunci: Ekstrak Daun Mengkudu, Telur Tetas Burung Puyuh dan Mortalitas Embrio.

\begin{abstract}
The research aims to know the effect of natural sanitation of Noni leaf extract (Morinda citrifoli lignosae) by wiping method on mortality of quail embryo eggs (Conturnix conturnix japonica). This research used 1.500 eggs of quail hatchlings with a ratio of male and female 1: 4 . This research used a completely randomized design method (CRD), with 3 treatments and 3 replications each consisting of 100 eggs hatching quails with an egg weight of 10 grams. The treatment used is P0: control, P1: using commercial disinfectant: $8 \mathrm{~mL} / 1000 \mathrm{~mL}$ Water, P2: 10\% concentration $=10 \mathrm{~mL}$ noni leaf extract $+90 \mathrm{~mL}$ distilled water. The results of the study with the use of Noni leaf extract as natural sanitation with the wiping method showed that the use of Noni extract of $10 \%$ did not provide a significant
\end{abstract}


difference in embryo fertility and mortality ( $\mathrm{P}>0.05)$. However, at a concentration of $10 \%$ can reduce embryo mortality $8 \%$. The conclusion of this research that the use of Noni leaf extract can affect embryo mortality.

Keywords: Noni Leaf Extract, Quail Hatching Eggs, and Embry Mortality.

\section{PENDAHULUAN}

Pembangunan peternakan merupakan bagian dari pembangunan nasional yang bertujuan untuk menyediakan pangan hewani berupa daging, susu, serta telur yang bernilai gizi tinggi, serta meningkatkan pendapatan peternak serta menambah devisa dan memperluas kesempatan kerja. Masa yang akan datang diharapkan pembangunan peternakan dapat memberikan kontribusi yang nyata dalam pembangunan perekonomian Indonesia. Salah satu jenis ternak yang cukup menjanjikan untuk diternakan adalah burung puyuh, jenis burung ini relative cukup kecil bila dibandingkan jenis ternak lainnya, pemeliharaan burung puyuh juga tidak begitu sulit, akan tetapi membutuhkan keuletan, kehati-hatian dan juga berkesinambungan.

Burung puyuh (Conturnix conturnix japonica) merupakan salah satu jenis burung yang tidak dapat terbang memiliki ukuran tubuh yang relatif kecil, memiliki kaki yang pendek dapat diadu dan bersifat kanibal. Awalnya burung puyuh merupakan burung liar. Pada tahun 1870 di Amerika Serikat, puyuh mulai diternakan dan setelah masa itu, puyuh terus berkembang dan menyebar ke seluruh dunia. Burung Puyuh di Indonesia, mulai dikenal dan diternakkan pada akhir tahun 1979. Peternakan di Indonesia masih skala kecil atau sampingan dengan pemeliharaan secara ekstensif dengan sistem masi tradisional dan adapun peternakan burung puyuh sebagai usaha pokok dengan pemeliharaan secara intensif (Anonim, 2002).

Bidang peternakan khususnya dalam peternakan ayam, masalah yang dihadapi adalah bagaimana untuk menetaskan telur ayam dalam jumlah banyak dan dalam waktu yang bersamaan. Karena kemampuan induk ayam dalam mengerami telurnya terbatas, yaitu maksimal 10 butir telur tiap induk ayam. Ini menjadi masalah yang serius karena kebutuhan daging dan telur ayam di pasar yang sangat banyak. Oleh karena itu salah satu cara yang dilakukan dengan menggunakan mesin tetas baik mesin tetas tradisional maupun internasional untuk meningkatkan daya tetas anak puyuh (Suprapto dkk., 2018).

Tanaman mengkudu (Morinda citrifolia lignosae) adalah salah satu tanaman yang sudah dimanfaatkan sejak lama hampir diseluruh belahan dunia. Daun mengkudu memilki 
kandungan kimia yang terdiri dari asetil ester, asam kapril, morinda dior dan morondin (Tampubolon, 1995). Selanjutnya daun mengkudu memiliki zat aktif yaitu minyak atsiri, alkaloid, aponin, flavoniud dan polifenol. Dapun zat aktif yang paling utama didalam daun mengkudu yaitu terpenoid, antibakteri, ascorbic acid, beta karoten dan prexerronine. Daun mengkudu juga mengandung antraquinon dan scolopetin yang aktif sebagai antimikroba, terutama bakteri. Oleh karena itu daun mengkudu banyak dimanfaatkan sebagai obat tradisional dan sebagai sanitasi alami (Sitepu dan Josua 2012).

Sanitasi atau pembersihan terhadap telur dan peralatan penetasan dapat dilakukan dengan menggunakan bahan yang bersifat membunuh mikroorganisme, seperti bakteri yang dapat mempengaruhi daya tetas telur. Salah satu jenis desinfektan yang banyak digunakan dalam proses penetasan adalah formaldehyde, penggunaan desinfektan dengan konsentrasi tinggi saat perkembangan embrio dapat menyebabkan abnormalitas embrio. Sanitasi suatu langka yang dilakukan ketika melakukan penetasa agar mikroorganisme dalam suatu penetasan tidak berkembang biak (Nandhra dkk., 2014).

Jenis desinfektan yang biasa digunakan dalam proses sanitasi antara lain, iodin, alkohol, kalium permanganat dan fenol. Namun beberapa dari desinfektan ini bersifat toksik, berbau tidak sedap dan menyebabkan iritasi. Sanitasi tingkat rendah tidak membunuh bibit penyakit, serta sanitasi terlalu tinggi dapat membunuh embrio telur sehingga dapat mempengaruhi fertilitas dan daya tetas telur. Oleh sebab itu perlu dilakukan penelitian mengenai bahan alami yang mampu meningkatkan daya tetas dan bobot tetas dan menurungkan fertilitas dan mortalitas embrio.

Uraian di atas maka penulis tertarik untuk melakukan penelitian tentang pengaruh sanitasi alami ekstrak daun mengkudu (Morinda citrifoli lignosae) dengan metode pengelapan terhadap mortalitas embrio telur tetas burung puyuh (Conturnix conturnix japonica).

\section{METODE}

\section{Prosedur Penelitian}

Penelitian ini merupakan penelitian eksperimen (kuantitatif) dengan metode Rancangan Acak Lengkap (RAL), dengan 3 perlakuan dan 3 ulangan masing-masing setiap ulangan terdiri dari 100 butir telur puyuh, sehingga total telur puyuh yang digunakan sebanyak 1.500 butir.

$\mathrm{P}_{0}$ : Kontrol 
$\mathrm{P}_{1}$ : Menggunakan Deksinfektan Komersil : $8 \mathrm{~mL} / 1000 \mathrm{~mL}$ Air

$\mathrm{P}_{2}$ : Konsentrasi 10\% = $10 \mathrm{~mL}$ Estrak Daun Mengkudu $+90 \mathrm{~mL}$ Air suling

\section{Pembuatan Ekstrak Daun Mengkudu}

Prosedur ekstraksi daun mengkudu dimulai dari daun mengkudu dewasa segar yang diambil dari Samata Integrated Farming System (SIFS) Kabupaten Gowa. Daun dewasa yang telah diambil sebanyak $2 \mathrm{~kg}$ dilayukan atau dijemur selama 3-4 jam, kemudian dikeringkan dalam oven selama 36 jam pada suhu $60^{\circ} \mathrm{C}$. Daun yang telah dikeringkan, kemudian dipotong-potong kecil dan diblender dengan halus dan dihasilkan tepung daun mengkudu sebanyak \pm 500 gram. Sampel berbentuk tepung tersebut kemudian dicampurkan dengan pelarut metanol 90\% dengan perbandingan 1:5 (500 gram tepung daun mengkudu dengan $2500 \mathrm{ml}$ pelarut methanol 90\%). Campuran dimaserasi dan wadah maserasi ditutup dengan menggunakan aluminium foil dan didiamkan selama 24 jam ditempat yang terlindung dari sinar matahari langsung sambil sesekali di aduk kemudian disaring untuk memisahkan ampas dan filtrat (Wati, 2009). Hasil saringan berupa filtrat diuapkan menggunakan rotary evaporator pada suhu $50{ }^{\circ} \mathrm{C}$ dengan kecepatan $80 \mathrm{rpm}$ selama \pm 5 jam sampai metanol yang terdapat di dalam campuran menguap. Selanjutnya ekstrak yang diperoleh kemudian diambil dan dibuat sesuai konsentrasi yaitu $10 \%$, yang dikonversi senilai $10 \mathrm{~mL}$.

\section{Pengelapan Telur Tetas}

Telur tetas burung puyuh yang telah diseleksi selanjutnya dilakukan pengelapan dengan menggunakan kapas yang dibasahi bahan sanitasi kimia berupa desinfektan komersil dan sanitasi alami berupa ekstrak daun mengkudu konsentrasi 10\% lalu anginanginkan selama \pm 24 jam lalu dimasukkan kedalam mesin tetas, tunggu hingga 17-18 hari dan diamati hasilnya.

\section{Inkubasi Telur Tetas}

Penelitian ini menggunakan 3 mesin tetas dan setiap mesin tetas dilengkapi 4 lampu dengan tegangan 15 watt sebagai pemanas, thermostat pengatur suhu dan hidrometer indikator kelembaban. Sebelum digunakan suhu mesin tetas diatur $\pm 38.5{ }^{\circ} \mathrm{C}$ dengan kelembaban $70-80 \%$ dan dibersihkan dari sisa kotoran penetasan sebelumnya. 


\section{Perhitungan Mortalitas Embrio}

Mortalitas embrio pada akhir penetasan dikatahui dengan cara memecahkan telur dan melihat embrio yang mati pada umur 1 hari dan umur 15 hari, kemudia mencatat jumlah yang tingkat mortalitas embrio tersebut.

\section{Analisis Data}

Data yang diperoleh akan dianalisis ragam berdasarkan Rancangan Acak Lengkap (RAL), dengan 3 perlakuan dan 3 ulangan. Apabila hasil penelitian menunjukkan berpengaruh nyata $(\mathrm{P}<0.05)$, maka dilanjutkan dengan uji Beda Nyata Terkecil $(B N T)$, yang dapat dihitung dengan model statistik.

\section{HASIL DAN PEMBAHASAN}

Hasil penelitian selama 55 hari yang yang mencangkup mortalitas embrio yang terdapat pada Diagram 1 dibawah ini:

Tabel 1. Rata-rata presentse mortalitas embrio (Me) telur tetas burung puyuh.

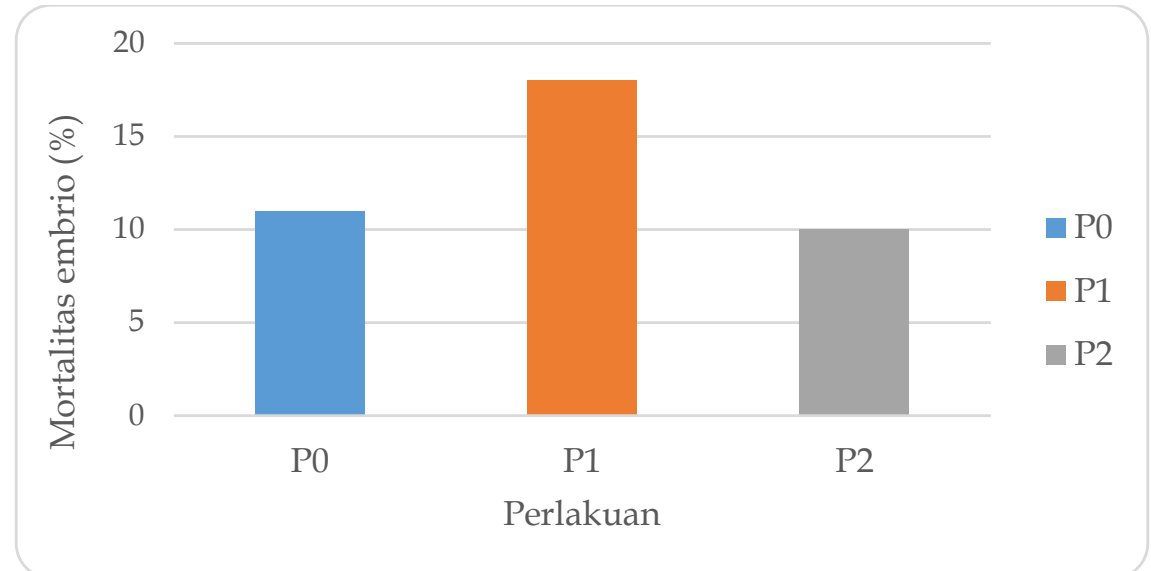

Keterangan : $\mathrm{P}_{0}$ : Kontrol, $\mathrm{P}_{1}$ : (Menggunakan Deksinfektan Komersil: 8 mL /1000 mL Air), $\mathrm{P}_{2}$ : Konsentrasi 10\% = (10 mL Estrak Daun Mengkudu + $90 \mathrm{~mL}$ Air suling $)$,

Hasil analisis sidik ragam menunjukkan bahwa perlakuan pemberian ekstrak daun mengkudu (Morinda citrifolia lignosae) pada konsentrsi 10\% tidak berpengaruh nyata $(\mathrm{P}>0,05)$ terhadap presentase mortalitas embrio telur tetas burung puyuh (Coturnix-coturnix japonica).

\section{Mortalitas Embrio}

Mortalitas embrio merupakan kematian yang terjadi pada saat embrio didalam cangkang sampai saat embrio keluar dari cangkang telur. Kematian embrio didalam telur umumnya terjadi dalam periode awal penetasan dan periode akhir penetasan. Untuk 
mengetahui mortalitas embrio dengan cara memecahkan telur yang tidak menetas pada akhir penetasan (Ningtyas dkk., 2013).

Perlakuan dengan konsentrasi 10\% ekstrak daun mengkudu memiliki rataan sebesar $14 \pm 5.85 \%$, lebih baik dari kontrol, desifektan komersil karena dapat menurunkan mortalitas embrio. Hal ini diduga ekstrak daun mengkudu tidak terlalu pekat, sehingga zat antimikroba bekerja secara optimal seperti minyak atsiri yang dapat menghambat mikroorganisme. Menurut Nandhra dkk., (2014), bahwa penggunaan ekstrak daun sirih 10\% dengan cara pencelupan memiliki rata-rata $47.62 \pm 18.44 \%$ ini lebih baik dari $\mathrm{P}_{0}$ dan $\mathrm{P}_{1}$ keadaan ini dipengaruhi oleh tekstur ekstrak daun sirih yang terlalu pekat yang akhirnya lengket pada kerabang telur membuat embrio mati. Menurut Ghofir dkk., (2014) menjelaskan bahwa konsentrasi $10 \%$ bisa efektif mencegah tumbuhnya bakteri pada telur salah satunya Salmonella typhimurium dan ekstrak daun sirih mengandung minyak atsiri yang bersifat menghambat pertumbuhan mikroba dan jamur.

Banyaknya tingkat mortalitas embrio pada awal penetasan dengan ditandainya pada telur yang sudah dipecahkan dengan warna kuning telur keruh dan terdapat sel benih yang utuh. Dan dua hari sebelum menetas ciri-ciri yang terlihat pada telur saat dipecahkan yaitu tidak terbentuknya semua organ, cangkan sudah pecah tetapi tidak menetas sempurna, poripori cangkan tertutupi sehingga tidak dapat bernapas dan pengaturan suhu dalam mesin tetas. Menurut Zamzamy dkk., (2014), bahwa ekstrak beluntas yang terlalu pekat menutupi pori-pori telur sehingga embrio banyak yang mati (Dead embryo). Embrio yang mati akan cepat membusuk setelah dilakukan proses pembasahan telur. Air dari proses pembasahan menyebabkan kelembaban telur tinggi. Cemaran bakteri patogen dapat terjadi pada kondisi suhu dan kelembapan yang tinggi karena perkembangannya optimal. Menurut Mukhlisah, (2014), bahwa kandungan bakteri yang tinggi menyebabkan telur explode karena bakteri pada embrio yang mati mengeluarkan $\mathrm{CO}_{2}, \mathrm{NH}_{3}, \mathrm{~N}_{2}$ dan $\mathrm{H}_{2} \mathrm{~S}$. Menurut Alkhakim dkk., (2016), bahwa mikroorganisme didalam telur lebih mudah berkembang hingga menyebabkan kematian embrio. Telur itik yang ditetaskan harus bersih dari berbagai kotoran yang melekat pada kerabang telur agar tidak mudah terkontaminasi oleh bakteri yang masuk melalui pori-pori pada kerabang telur yang bisa menyebabkan kematian embrio. Salah satu yang menyebabkan telur rusak saperti kebersihan cangkang karena terkontaminasi oleh feses dan mikroba. Kerusakan telur tetas umumnya terjadi beberapa jam 
Isra Mirawati dkk., $\mid 113$

JiiP Volume 6 Nomor 2: 107-114, Desember 2020

setelah ditelurkan, karena perubahan suhu telur dari suhu tubuh $\left(37^{\circ} \mathrm{C}\right)$ ke suhu kamar yang lebih rendah sehingga terjadi penyusutan isi telur.

Sanitasi alami dengan menggunakan ekstrak daun mengkudu dapat menurunkan mortalitas embrio dengan konsentrasi 10\% karena pada daun mengkudu terdapat senyawa aktif seperti minyak atsiri, alkohol, aldehid, keton, fenol, terpenoid dan tannin. Daun mengkudu memiliki kemampuan menghambat pertumbuhan bakteri Escherichia coli dan Salmonella sp (Sari, 2004).

Senyawa yang terdapat saat maserasi daun mengkudu yaitu fenol, triterpenoid, flavonoid dan antrakuinon. Menurut Karmila (2016), bahwa ekstrak daun mengkudu memiliki daya hambat terhadap pertumbuhan bakteri Escherichia coli dan Salmonella sp. Adanya kemempuan ekstrak daun mengkudu dalam menghambat pertumbuhan bakteri Escherichia coli dan Salmonella sp. Disebabkan bahwa ekstrak daun mengkudu memiliki kandungan senyawa yang aktif untuk berperan sebagai antimikroba seperti antroquinon, terpenoid dan senyawa lipid (bersifat seperti minyak atsiri).

\section{KESIMPULAN}

Berdasarkan hasil penelitian dengan penggunaan ekstrak daun mengkudu sebagai sanitasi alami dengan metode pengelapan diperoleh bahwa penggunaan ekstrak daun mengkudu $10 \%$ tidak memberikan perbedaan pengaruh yang nyata terhadap mortalitas embrio $(\mathrm{P}>0.05)$. Meskipun demikian pada konsentrasi 10\% dapat menurunkan mortalitas embrio $8 \%$.

\section{DAFTAR PUSTAKA}

Alkhakim, F. H., Muhammad, N.H., Galuh, D. F., Dewi, A dan Heli, T. 2016. Pengaruh Ekstrak Daun Kersen Terhadap Daya Tetas dan Mortalitas Telur Itik Hibrida. Jurnal Ilmu-Ilmu Peternakan, 26 (2), 8-13.

Anonim . 2002. Puyuh Si Mungil Penuh Potensi. Agromedia Pustaka. Jakarta

Ghofir, M., Sugihartono, M., Thomas, R. 2014. Efektivitas Pemberian Ekstrak Daun Sirih (Piper betle linn) Terhadap Penetasan Telur Ikan Gurami (Osphronemus gouramy lac). Jurnal Ilmiah Universitas Batanghari Jambi, 14 (1), 37-44.

Karmila. 2016. Daya Hambat Ekstrak Daun Mengkudu (Morinda Citrifolia Lignosae) Terhadap Pertumbuhan Bakteri Penyebab Diare. Skripsi. Makassar. Jurusan Biologi Fakultas Sains dan Teknologi Universitas Islam Negeri Alauddin Makassar.

Mukhlisah, A. N. 2014. Pengaruh Level Ekstrak Daun Melinjo (Gnetuin Gneinon Linn) dan Lama Penyimpanan yang Berbeda Terhadap Kulitasas Telur. Skripsi. Fakultas Peternakan. Universitas Hsanuddin. Makassar. 
Nandhra, I.P., Edy, S dan Hamiyanti, A.A. 2014. Pengaruh Penggunaan Ekstrak Daun Sirih (Piper betle linn) pada Pencelupan Telur Tetas Itik Mojosari Terhadap Daya Tetas dan Mortalitas Embrio. Jurnal Ilmu - Ilmu Peternakan, 25 (1), 16-23.

Ningtyas, M.S., Ismoyati, I.H. dan Sulityawan. 2013. Pengaruh Temperatur Terhadap Daya Tetas dan Hasil Tetas Telur Itik (Anas plathyrinchos). Jurnal Ilmiah Peternakan, 1 (1), 347-352.

Sari, K. S. 2004. Pengaruh Konsentrasi Suspense Bawang Putih Terhadap Pertumbuhan Staphylococcus aureus. Skripsi. Fakultas Matematika dan Ilmu Pengetahuan Alam, Universitas Negeri Padang. Padang.

Sitepu dan Josua. 2012. Perbandingan efektifitas daya hambat terhadap Staphylococcus Aureus dari Berbagai Jenis Ekstrak Buah Mengkudu (Morinda citrofolia lignosae) (In vitro). Skripsi. Universitas Sumatera Utara. Medan.

Suprapto. Anang, T dan Epyk, S. 2018. Rancang Bangun Mesin Penetas Telur Ayam Berbasis Mikrokontroler Dengan Fuzzy Logic Controller. Jurnal Teknik Elektro Industrik. Institut Teknologi Sepuluh Nopember (ITS) Surabaya.

Tampubolon, O.P. 1995. Tumbuhan Obat. Bhratara. Jakarta.

Wati, R.A. 2009. Efektivitas Pemberian Estrak Daun Mengkudu (Morinda citrifolia lignosae) Sebagai Pengganti Antibakteri Terhadap Performa Ayam Broiler yang Diinfeksi Salmonella thypimurium. Skripsi. Institut Pertanian Bogor. Bogor Agricultural University.

Zamzamy, S. P., Sudjarwo, E., Hamiyanti, A. A. 2014. Pengaruh Penggunaan Ekstrak Daun Beluntas (Pluchea Indica Less.) pada Pencelupan Telur Tetas Itik Mojosari Terhadap Daya Tetas dan Mortalitas Embrio. Jurnal Peternakan.,1 (1), 1-8. 